\title{
Evaluation of the dynamic pattern of viral evolution in patients with virological breakthrough during treatment with nucleoside/nucleotide analogs by ultra-deep pyrosequencing
}

\author{
SHAOLONG CHEN ${ }^{1 *}$, JING WU $^{1 *}$, ERLI GU ${ }^{1,2^{*}}$, YAOJIE SHEN ${ }^{3}$, FEIFEI WANG ${ }^{1,4}$ and WENHONG ZHANG ${ }^{1,3}$ \\ ${ }^{1}$ Department of Infectious Diseases, Huashan Hospital; ${ }^{2}$ Division of Gastroenterology and Hepatology, \\ Jing'an District Central Hospital, Jing'an Branch of Huashan Hospital, Fudan University, Shanghai 200040; \\ ${ }^{3}$ Institute of Biomedical Sciences, Fudan University; ${ }^{4}$ Key Laboratory of Medical Molecular Virology, \\ Department of Medical Microbiology and Parasitology, Shanghai Medical College, \\ Fudan University, Shanghai 200032, P.R. China
}

Received December 15, 2014; Accepted September 14, 2015

DOI: $10.3892 / \mathrm{mmr} .2015 .4577$

\begin{abstract}
Virological breakthrough is a clinical manifestation in patients infected with chronic hepatitis B (CHB), who undergo treatment with nucleoside/nucleotide analogs (NUCs). The current understanding of the underlying mechanism of virological breakthrough is limited. Ultra-deep pyrosequencing (UDPS) is a novel and powerful tool used to investigate minor viral variants and viral evolution. The present study used UDPS to investigate the viral evolution pattern during virological breakthrough in patients with $\mathrm{CHB}$ treated with NUCs. A total of 12 patients who experienced virological breakthrough were recruited in the present study. During the treatment with lamivudine, adefovir was added as a rescue therapy when virological breakthrough emerged, and the therapy was continued until week 96 . Serum samples from each patient were collected at different time points for UDPS analysis. Treatment with lamivudine resulted in an increased rate of the viral mutations, rtM204V/I, rtL180M and rtL80I. Virological breakthrough was accompanied by significant rtM204I/V substitutions in eight of the patients. A total of three types of rt204 mutation, associated with virological breakthrough, were observed, including YIDD variant-dominated, YVDD variant-dominated and YMDD wild-type-dominated virological breakthrough. YVDD variants reverted to the wild-type following the adefovir add-on rescue therapy, although the YIDD variants remained dominant following the
\end{abstract}

Correspondence to: Dr Wenhong Zhang, Department of Infectious Diseases, Huashan Hospital, Fudan University, 12 Wulumuqi Road, Shanghai 200040, P.R. China

E-mail: zhangwenhong@fudan.edu.cn

*Contributed equally

Key words: hepatitis B, ultra-deep pyrosequencing, virological breakthrough, lamivudine, adefovir combination therapy. The mechanism underlying virological breakthrough was revealed to be complex and associated with the rapid replication of mutated variants. UDPS analysis, therefore, provided a useful tool to investigate the dynamic evolution pattern of hepatitis B virus.

\section{Introduction}

Chronic hepatitis $\mathrm{B}(\mathrm{CHB})$ is a major global health problem, with 350 million individuals affected worldwide. Infection with the hepatitis B virus (HBV) is a major cause of the development of cirrhosis, decompensated liver disease and hepatocellular carcinoma (1). Therefore, therapies which effectively inhibit HBV replication and prevent the progression of HBV-associated liver diseases are urgently required $(2,3)$. Nucleoside/nucleotide analogs (NUCs) provide one of the currently available therapies for the management of $\mathrm{CHB}$, including lamivudine (LAM), adefovir (ADV), telbivudine, entecavir (ETV) and tenofovir (TDF) (4). NUCs are widely used for treating $\mathrm{CHB}$ due to a number of advantages, including the ease of oral administration, good tolerance and rapid viral suppression; however, long-term therapies with NUCs, particularly early approved NUCs, results in the emergence of viral mutations, which are responsible for virological, and subsequently, biochemical breakthrough, followed by a worsening of the liver disease (5). Virological breakthrough is the first manifestation of the disease, predominantly caused by resistance in patients treated with NUCs (6). Therefore, developing a further understanding of the underlying mechanism of virological breakthrough during treatment with NUCs may hold promise for the development of optimal strategies for NUC therapies, and the management of drug resistance. Currently, techniques which are available to investigate mutations in HBV are limited. Among them, Sanger sequencing is widely used for analyzing DNA sequences, although its usefulness is limited by its low sensitivity and the long duration required, in addition to an inability to perform haplotype analysis, which renders the method unsuited for investigating the mechanism that underlies the evolution of HBV quasispecies during 
treatment with NUCs (7). However, technological advances are improving the situation, including the development of next-generation sequencing techniques, which are capable of detecting minor and longitudinal drug-associated mutations (8). Ultra-deep pyrosequencing (UDPS) is based on the 454 sequencing technology, and it is useful for detecting thousands of clonally amplified sequences. UDPS has previously been applied to the investigation of $\operatorname{HIV}(9,10)$ and hepatitis $\mathrm{C}$ virus (HCV) (11-13), and noteworthy results were generated in these early studies. However, the data which have been obtained from the application of UDPS to HBV are limited, particularly regarding longitudinal studies of the dynamic pattern of viral evolution during antiviral therapy.

In the present study, the underlying mechanism of virological breakthrough in patients with $\mathrm{CHB}$ receiving NUCs was investigated using UDPS in the reverse transcriptase (RT) region of $\mathrm{HBV}$, and the dynamic viral evolution pattern during virological breakthrough was further investigated.

\section{Materials and methods}

Enrollment of the patients and the study design. Patients with $\mathrm{CHB}$, together with compensated cirrhosis, were selected from a prospective study, based on a treatment regimen over a 96 week period, which comprised combination therapy with LAM and ADV (14). Briefly, the patients were treated with LAM monotherapy for the first 24 weeks. At week 24, a decision was taken to switch to combination therapy or to continue with the monotherapy, according to the response of the patient to the treatment. Combination therapy was performed for all patients starting from week 48, and the treatment ended at week 96. For each patient, measurements of the DNA level of HBV were serially recorded at weeks $0,12,24,36,48,72$ and 96. Plasma samples were collected at weeks 0, 24, 36, 48 and 96 , and were subsequently stored at $-80^{\circ} \mathrm{C}$ prior to the UDPS analysis. A partial virological response was defined as a decrease in the level of HBV DNA of $>1 \log _{10} \mathrm{IU} / \mathrm{ml}$, but with detectable levels of HBV DNA remaining following 6 months of therapy in compliant patients (15). Virological breakthrough was defined as an increase of $>1 \log _{10} \mathrm{IU} / \mathrm{ml}$ in the level of the HBV DNA from nadir during the treatment (15). To investigate the mechanism underlying the virological breakthrough, patients were enrolled in the present study who experienced viral breakthrough and were receiving ADV add-on as a rescue therapy. The present study (ref. no. 07-05) was approved by the ethics committee of Jing'an District Central Hospital (Shanghai, China).

Polymerase chain reaction (PCR) amplification and 454 sequencing. The DNA from serum samples was extracted using a Qiagen ${ }^{\circledR}$ DNeasy Blood \& Tissue kit (Qiagen, Inc. Valencia, CA, USA), according to a previously published procedure (16). Briefly, the DNA was isolated and purified through a spin column, according to the manufacturer's instructions. The DNA was initially adsorbed onto the silica of the column, followed by several washes with wash buffer, containing $70 \%$ ethanol. The DNA was subsequently eluted from the column, prior to the PCR amplification of the RT region for the identification of mutations by 454 sequencing. The RT region sequence was divided into three overlapping fragments for PCR amplification. The template-specific sequences of the primer pairs used in the present study are listed in Table I. The full forward primers consisted of a directional GS FLX Titanium Primer A sequence (synthesized by Sangon Biotech Co., Ltd., Shanghai, China). A 10 base-pair barcode sequence upstream of the template-specific forward sequence was used for the identification of the samples. The reverse primers consisted of a GS FLX Titanium Primer B sequence barcode, in addition to the template-specific reverse sequence. The PCR cycling conditions were $94^{\circ} \mathrm{C}$ for $5 \mathrm{~min}$, followed by 30 cycles of denaturation at $94^{\circ} \mathrm{C}$ for $30 \mathrm{sec}$, annealing at $63^{\circ} \mathrm{C}$ for $30 \mathrm{sec}$ and extension at $72^{\circ} \mathrm{C}$ for $40 \mathrm{sec}$, using the Ex $\mathrm{Taq}^{\mathrm{TM}}$ DNA polymerase (Takara Bio, Inc., Dalian, China). The fragments were purified using a MinElute gel extraction kit (Qiagen, Inc.). The DNA concentration in the purified PCR products was measured using a PicoGreen quantification assay, according to the manufacturer's instructions (Invitrogen Life Technologies, Carlsbad, CA, USA). The barcoded samples were pooled with the identical quantity of DNA from each sample, and the pooled PCR products were subjected to standard 454 DNA sequencing, according to the manufacturer's instructions (GS FLX system; 454 Life Sciences, Branford, CT, USA).

Data and statistical analysis. The 454-generated FASTA (.fna) and quality score (.qual) files were obtained as raw sequence data. The multiplexed reads were split and assigned to samples on the basis of their unique nucleotide barcode. The sequences were screened, trimmed and filtered using programs written by Encode Genomics (Suzhou, China), and the qualified sequence fragments were subsequently used for Basic Local Alignment Search Tool (BLAST) analysis to identify the mutations, by comparing with the sequence of the HBV RT region as the reference from the National Center for Biotechnology Information database (http://www.ncbi.nlm. nih.gov). The perl script for formatting the data for BLAST analysis was designed in-house. Sequences which were too short ( $<50 \mathrm{bp})$ and sequences with a low-quality score were removed. After having calculated that the mutation rate for the clean data was $<1$, a cut-off of $1 \%$ was used to differentiate an authentic variant from a possible artificial error, therefore, only a mutation rate $>1$ was considered to indicate the real existence of the mutation in the RT region (17). All data were analyzed using the SPSS 19.0 statistical software package (IBM SPSS, Chicago, IL, USA), and all continuous variables are expressed as the median (range). All P-values were two-sided and $\mathrm{P}<0.05$ was considered to indicate a statistically significant difference.

\section{Results}

Baseline characteristics of the patients. A total of 12 patients (patients A-L) with CHB were enrolled in the present study. The patients were initially treated with LAM monotherapy, and ADV was added to the regimen as a rescue therapy once the patients experienced virological breakthrough (with the exception of patient $\mathrm{C}$, who received ADV prior to the virological breakthrough due to only a partial response to LAM). The combination therapy lasted until week 96 . The baseline characteristics of the patients enrolled in this study are summarized in Table II. A total of 10/12 patients were $\mathrm{HBeAg}$ positive prior to 
Table I. Oligonucleotide primers used for polymerase chain reaction amplification and deep sequencing of $\mathrm{HBV}$ reverse transcriptase genes.

\begin{tabular}{ll}
\hline Primer & \multicolumn{1}{c}{ Sequence } \\
\hline HBV-F1 & 5'-CTGCTGGTGGCTCCAGTT-3' \\
HBV-R1 & 5'-GCAGGTCTTGCATGGTCCCGT-3' \\
HBV-F2 & 5'-ATGTTGCCCGTTTGTCCTC-3' \\
HBV-R2 & 5'-CCCAACTTCCAATTACATA-3' \\
HBV-F3 & 5'-TAATAAAACCAAACGTTGGGGC-3' \\
HBV-R3 & 5'-AGGAGTTCCGCAGTATGGAT-3' \\
\hline
\end{tabular}

HBV, hepatitis B virus; F, forward; R, reverse.

the treatment. Among these patients, only patient $\mathrm{K}$ experienced a HBeAg seroconversion during the treatment with LAM. The mean age of the 12 patients was $47 \pm 10.03$ years, and the mean baseline levels of alanine transminase and aspartate transaminase levels were $67.31 \pm 30.83$ and $49.87 \pm 16.79$ IU/L respectively.

Mutation of the HBV RT region detected by UDPS at different time points during the treatment. UDPS was performed to investigate the emergence of any drug resistance-associated mutations in the 12 patients at weeks $0,24,36,48$ and 96 during the therapy, representing a total of 54 serial samples (six of the serum samples were too low to perform a UDPS assay). A total of 345,025 sequences were generated, with 6,389 \pm 916 sequences per sample and a mean length of $380 \pm 117$ nucleotides, following the elimination of unqualified and excessively short sequences $(<50 \mathrm{bp})$.

The whole RT region was evaluated for each patient, and the rates of the mutation sites for the 12 patients at the different time points are summarized in Table III. Although all 12 patients experienced viral breakthrough during the treatment with LAM, low rates of drug resistance-associated mutations were observed at week 0 prior to the treatment, with the exception of patient D, who exhibited a rate of 94.03 for M204I, and patient $\mathrm{G}$, who exhibited a rate of 97.59 for A181V. Upon the initiation of the LAM monotherapy, which was accompanied by a decrease in the DNA level of HBV, the HBV DNA evolved on an individual basis, although several common characteristics were observed. The mutation rates of LAM-resistance-associated sites, including rt204, rt180 and rt80, slowly increased following the initiation of the LAM monotherapy, and the combination therapy resulted in an increase in the mutation rates at ADV-resistance-associated sites, including rt181 and rt236 (Table III). Notably, the mutation rate of rtM204I/V was markedly increased at the time of virological breakthrough in eight patients, and this was accompanied by an increased mutation rate of rtL180M and/or rtL80I/V. In addition, different HBV evolution profiles were observed during the ADV add-on therapy.

Patterns of viral evolution in the patients with LAM-induced virological breakthrough. Since the above results suggested that the marked mutation rate observed at the rt204 site was the predominant cause of the virological breakthrough, the 12 patients were further divided into three groups on the basis of the type of rt204 mutation. Notably, common characteristics were observed in the three types of rt204 mutation-associated virological breakthrough.

YIDD-motif-variant-dominated virological breakthrough. Virological breakthrough in patients A, B, C and D was dominated by the YIDD motif variant, since their virological breakthrough was caused by a markedly increased mutation rate of M204I during the LAM treatment. As shown in Fig. 1, the characteristics in common of these four patients were that the viral breakthrough was caused by the high rate of M204I mutation during the treatment with LAM, and that the domination of the M204I mutation continued following the ADV add-on therapy. Furthermore, the increased mutation rate of rt180 or rt80 was accompanied by the occurrence of the high mutation rate of M204I during the virological breakthrough (Fig. 1 and Table III).

YVDD-motif-variant-dominated virological breakthrough. This group included patients E, F, G and H, and their viral breakthroughs were predominantly caused by the YVDD motif variant. As shown in Fig. 2, the M204V mutation in patients $\mathrm{E}$ and $\mathrm{F}$ eventually disappeared following the ADV add-on therapy, which also occurred in the other two patients. In all four patients, the M204V mutation was accompanied by the L180M mutation, and an identical trend was observed in the two mutation sites (Table III).

YMDD-wild-type-dominated virological breakthrough. YMDD-wild-type-dominated virological breakthrough was identified in patients $\mathrm{H}, \mathrm{I}, \mathrm{J}$ and $\mathrm{K}$. This type of virological breakthrough was observed in the patients lacking any mutation of the YMDD motif (Fig. 3). The level of HBV DNA in these four patients declined following the ADV add-on therapy. The YMDD wild-type motif persisted during the treatment with LAM monotherapy or the LAM + ADV combination therapy.

\section{Discussion}

Virological breakthrough is a clinical manifestation in the treatment of $\mathrm{CHB}$, which is defined as an increase of $\geq 1 \log _{10}$ IU/ml compared with nadir during treatment in patients with good adherence (15). Virological breakthrough during the treatment of CHB was predominantly caused by drug resistance, although its underlying mechanism remains to be fully elucidated $(18,19)$. The mutation rate identified for the recently approved NUCs, including ETV and TDF, is very low. ETV and TDF accounted for 1.5 and 0 of the identified drug resistance rate, respectively, in patients who had received 5 years of treatment (15). However, the situation is less optimistic as far as the early approved NUCs is concerned, including LAM, which continues to be widely used in developing countries (20). It was reported that LAM, with a low genetic barrier to resistance, resulted in drug-resistant mutations in $70 \%$ of the patients following 5 years of treatment (15). The risk of drug resistance is associated with high baseline levels of HBV DNA, the administration of a low-genetic-barrier drug and a gradual decrease in the level of HBV DNA during treatment, which creates an environment 
Table II. Baseline characteristics of the 12 patients enrolled in the present study.

\begin{tabular}{lcccccc}
\hline Patient no. & Age (year) & Gender & $\begin{array}{c}\text { HBV } \\
\text { e antigen status }\end{array}$ & $\begin{array}{c}\text { HBV DNA level } \\
\left(\log _{10} \text { IU/ml }\right)\end{array}$ & ALT (IU/L) & HBsAg (IU/ml) \\
\hline A & 48 & M & + & 6.50 & 82 & $2,118.03$ \\
B & 36 & M & + & 6.15 & 54 & \\
C & 48 & F & - & 8.04 & 96 & $8,938.29$ \\
D & 60 & F & + & 8.00 & 107 & 118.50 \\
E & 55 & M & - & 5.13 & 52 & $1,587.81$ \\
F & 43 & M & + & 6.39 & 114 & $1,933.33$ \\
G & 43 & M & + & 6.99 & 69 & $1,239.75$ \\
H & 59 & M & + & 7.33 & 77 & $3,443.97$ \\
I & 30 & M & + & 6.11 & 35 & $2,558.67$ \\
J & 61 & F & + & 8.04 & 30 & $4,053.79$ \\
K & 39 & M & + & 6.05 & 76 & 998.37 \\
L & 42 & F & + & 5.40 & 16 & 156.86 \\
\hline
\end{tabular}

HBV, hepatitis B virus; ALT, alanine transaminase; M, male; F, female.
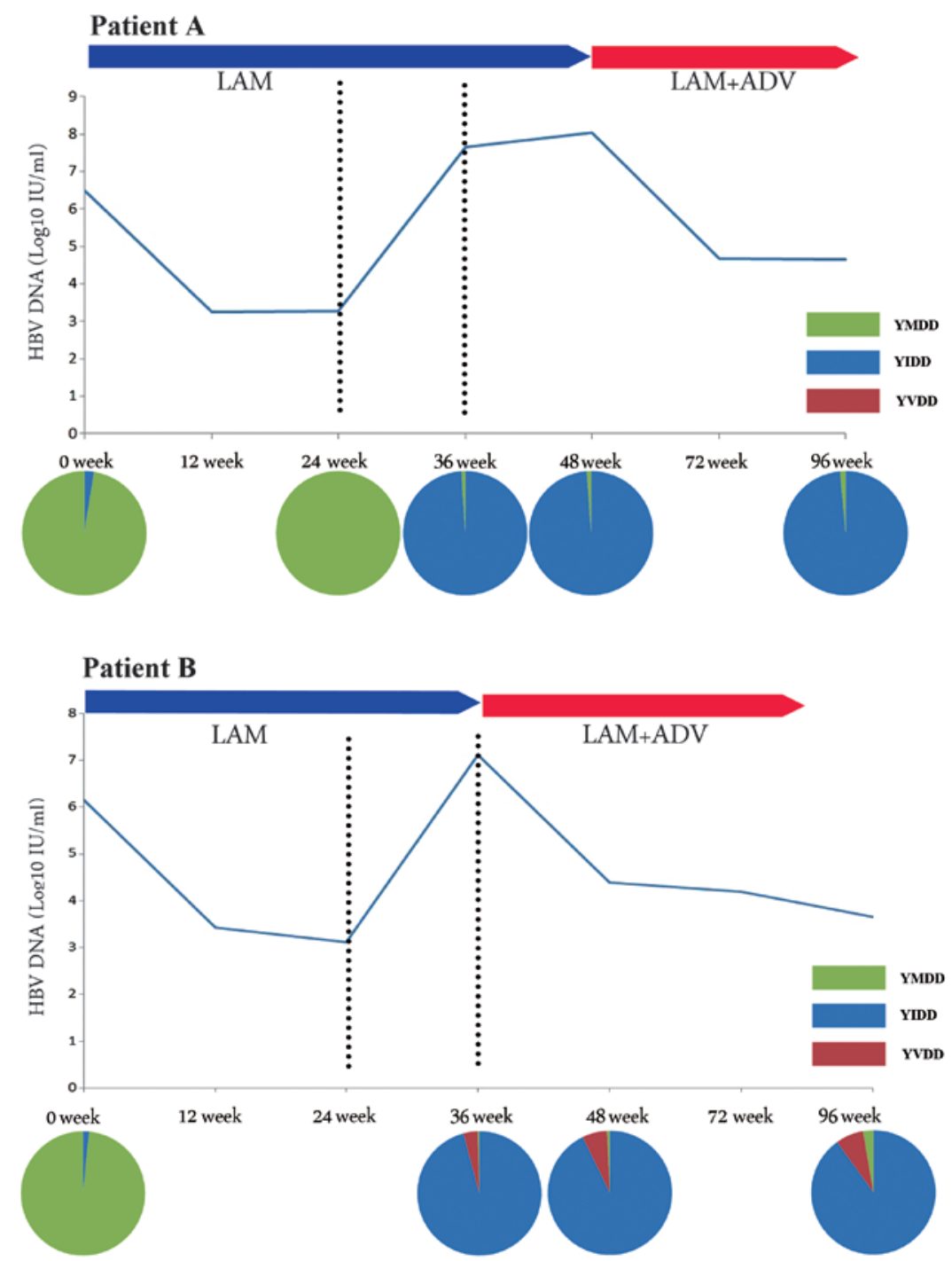

Figure 1. YIDD motif-variant-dominated viral breakthrough in 4/12 patients in the present study. The virological breakthrough was observed in patients A, $\mathrm{B}, \mathrm{C}$ and $\mathrm{D}$, although this figure only illustrates the dynamic evolution pattern of rt204 and the HBV DNA level in patients A and B. The absolute quantity of HBV DNA during the virological breakthrough was dominated by the YIDD motif variant, which remained stable following combination therapy. ADV, adefovir; LAM, lamivudine; HBV, hepatitis B virus. 
Table III. Mutation rates detected using ultra-deep pyrosequencing analysis in the 12 patients at different time points during the treatment.

\begin{tabular}{|c|c|c|c|c|c|c|}
\hline \multirow[b]{2}{*}{ Patient } & \multirow[b]{2}{*}{ Mutation site } & \multicolumn{5}{|c|}{ Mutation rates $(\%)$ at various weeks post-therapy } \\
\hline & & 0 & 24 & 36 & 48 & 96 \\
\hline \multirow[t]{11}{*}{ Patient A } & L180M & $*$ & $*$ & $*$ & $*$ & $*$ \\
\hline & A181S & $*$ & $*$ & $*$ & $*$ & $*$ \\
\hline & A181T & $*$ & $*$ & 1.63 & 1.72 & 3.89 \\
\hline & A181V & $*$ & $*$ & $*$ & $*$ & $*$ \\
\hline & M204I & 2.52 & $*$ & 99.01 & 98.86 & 98.55 \\
\hline & M204V & $*$ & $*$ & $*$ & $*$ & $*$ \\
\hline & N236T & $*$ & $*$ & $*$ & $*$ & $*$ \\
\hline & M250I & $*$ & $*$ & $*$ & $*$ & 1.54 \\
\hline & M250L & $*$ & $*$ & $*$ & $*$ & $*$ \\
\hline & L80I & $*$ & $*$ & 96.19 & 96.71 & 95.78 \\
\hline & L80V & $*$ & $*$ & $*$ & $*$ & $*$ \\
\hline \multirow[t]{11}{*}{ Patient B } & L180M & $*$ & a & 5.01 & 8.45 & 7.96 \\
\hline & A181S & $*$ & a & $*$ & $*$ & $*$ \\
\hline & A181T & 1.08 & a & 1.01 & 3.87 & 3.30 \\
\hline & A181V & $*$ & $\mathrm{a}$ & $*$ & $*$ & $*$ \\
\hline & M204I & 1.57 & a & 95.84 & 92.76 & 90.05 \\
\hline & M204V & $*$ & a & 3.74 & 6.49 & 7.26 \\
\hline & N236T & $*$ & a & $*$ & $*$ & $*$ \\
\hline & M250I & $*$ & a & $*$ & 2.43 & 1.91 \\
\hline & M250L & $*$ & a & $*$ & $*$ & $*$ \\
\hline & L80I & $*$ & a & 1.3 & 2.65 & $*$ \\
\hline & L80V & $*$ & $\mathrm{a}$ & $*$ & $*$ & $*$ \\
\hline \multirow[t]{11}{*}{ Patient C } & L180M & $*$ & 9.26 & $*$ & 1.31 & a \\
\hline & A181S & $*$ & 1.23 & $*$ & $*$ & a \\
\hline & A181T & $*$ & 2.77 & $*$ & 5.97 & a \\
\hline & A181V & $*$ & $*$ & $*$ & $*$ & $\mathrm{a}$ \\
\hline & M204I & $*$ & 13.35 & 98.82 & 98.53 & a \\
\hline & M204V & $*$ & $*$ & $*$ & $*$ & a \\
\hline & N236T & $*$ & 5.41 & $*$ & $*$ & a \\
\hline & M250I & $*$ & $*$ & $*$ & 2.04 & a \\
\hline & $\mathrm{M} 250 \mathrm{~L}$ & $*$ & $*$ & $*$ & $*$ & a \\
\hline & L80I & $*$ & $*$ & 96.46 & 95.71 & a \\
\hline & L80V & $*$ & $*$ & $*$ & $*$ & $\mathrm{a}$ \\
\hline \multirow[t]{11}{*}{ Patient D } & L180M & 8.81 & 16.07 & 35.06 & 40.14 & 38.23 \\
\hline & A181S & $*$ & $*$ & $*$ & * & $*$ \\
\hline & A181T & 3.51 & 1.19 & 3.17 & 3.11 & 2.63 \\
\hline & A181V & $*$ & $*$ & $*$ & $*$ & $*$ \\
\hline & M204I & 94.03 & 93.96 & 99.00 & 99.41 & 99.27 \\
\hline & M204V & $*$ & $*$ & $*$ & $*$ & $*$ \\
\hline & N236T & $*$ & $*$ & $*$ & $*$ & $*$ \\
\hline & M250I & 1.67 & 1.66 & 3.90 & 5.04 & 3.66 \\
\hline & M250L & $*$ & $*$ & $*$ & $*$ & $*$ \\
\hline & L80I & 16.80 & 23.00 & 65.55 & 49.55 & $*$ \\
\hline & L80V & 5.84 & 3.34 & 3.80 & 3.81 & $*$ \\
\hline \multirow[t]{4}{*}{ Patient E } & L180M & $*$ & $*$ & 98.38 & 97.40 & 1.73 \\
\hline & A181S & $*$ & $*$ & $*$ & $*$ & $*$ \\
\hline & A181T & 1.63 & 2.58 & $*$ & 2.60 & 2.44 \\
\hline & A181V & 6.19 & $*$ & $*$ & $*$ & $*$ \\
\hline
\end{tabular}


Table III. Continued.

\begin{tabular}{|c|c|c|c|c|c|c|}
\hline \multirow[b]{2}{*}{ Patient } & \multirow[b]{2}{*}{ Mutation site } & \multicolumn{5}{|c|}{ Mutation rates (\%) at various weeks post-therapy } \\
\hline & & 0 & 24 & 36 & 48 & 96 \\
\hline & M204I & 2.41 & 2.17 & $*$ & $*$ & 5.70 \\
\hline & M204V & $*$ & $*$ & 99.26 & 99.25 & $*$ \\
\hline & N236T & 8.21 & 4.30 & $*$ & $*$ & 8.76 \\
\hline & M250I & $*$ & $*$ & $*$ & 4.73 & $*$ \\
\hline & M250L & $*$ & $*$ & $*$ & $*$ & $*$ \\
\hline & L80I & $*$ & * & $*$ & $*$ & * \\
\hline & L80V & $*$ & $*$ & $*$ & $*$ & $*$ \\
\hline \multirow[t]{11}{*}{ Patient F } & L180M & $*$ & $*$ & 79.20 & 1.28 & 5.51 \\
\hline & A181S & $*$ & $*$ & $*$ & $*$ & $*$ \\
\hline & $\mathrm{A} 181 \mathrm{~T}$ & $*$ & * & $*$ & 1.15 & 7.75 \\
\hline & $\mathrm{A} 181 \mathrm{~V}$ & $*$ & $*$ & $*$ & $*$ & $*$ \\
\hline & M204I & 1.71 & $*$ & 18.05 & 11.26 & 42.47 \\
\hline & M204V & $*$ & $*$ & 78.29 & $*$ & 1.16 \\
\hline & $\mathrm{N} 236 \mathrm{~T}$ & $*$ & $*$ & $*$ & 4.47 & $*$ \\
\hline & M250I & $*$ & $*$ & $*$ & $*$ & $*$ \\
\hline & M250L & $*$ & $*$ & $*$ & $*$ & $*$ \\
\hline & L80I & $*$ & $*$ & 5.05 & 3.53 & 5.28 \\
\hline & L80V & $*$ & $*$ & 8.15 & $*$ & $*$ \\
\hline \multirow[t]{11}{*}{ Patient G } & L180M & $*$ & 94.98 & 91.92 & 100 & 45.59 \\
\hline & A181S & $*$ & * & * & $*$ & $*$ \\
\hline & $\mathrm{A} 181 \mathrm{~T}$ & $*$ & $*$ & $*$ & $*$ & 7.63 \\
\hline & $\mathrm{A} 181 \mathrm{~V}$ & 97.59 & 98.72 & 99.17 & 100 & 83.05 \\
\hline & M204I & $*$ & $*$ & $*$ & $*$ & $*$ \\
\hline & M204V & $*$ & 97.36 & 91.64 & 100 & 48.17 \\
\hline & $\mathrm{N} 236 \mathrm{~T}$ & $*$ & $*$ & $*$ & $*$ & 7.57 \\
\hline & M250I & $*$ & $*$ & $*$ & $*$ & $*$ \\
\hline & M250L & $*$ & $*$ & $*$ & $*$ & $*$ \\
\hline & L80I & $*$ & $*$ & $*$ & $*$ & $*$ \\
\hline & L80V & $*$ & $*$ & $*$ & $*$ & $*$ \\
\hline \multirow[t]{11}{*}{ Patient $\mathrm{H}$} & L180M & $*$ & 29.09 & 82.49 & 34.69 & 16.60 \\
\hline & A181S & $*$ & $*$ & $*$ & $*$ & $*$ \\
\hline & $\mathrm{A} 181 \mathrm{~T}$ & $*$ & $*$ & $*$ & $*$ & $*$ \\
\hline & A181V & $*$ & $*$ & $*$ & $*$ & $*$ \\
\hline & M204I & 2.55 & $*$ & 2.86 & 64.62 & 82.73 \\
\hline & M204V & $*$ & 27.82 & 83.93 & 34.08 & 16.40 \\
\hline & $\mathrm{N} 236 \mathrm{~T}$ & $*$ & $*$ & $*$ & $*$ & $*$ \\
\hline & M250I & $*$ & $*$ & $*$ & $*$ & $*$ \\
\hline & M250L & $*$ & $*$ & $*$ & $*$ & 1.46 \\
\hline & L80I & $*$ & 1.33 & 3.37 & 1.91 & $*$ \\
\hline & L80V & $*$ & $*$ & 31.55 & 18.36 & 7.83 \\
\hline \multirow[t]{9}{*}{ Patient I } & L180M & $*$ & $*$ & $*$ & $*$ & $*$ \\
\hline & A181S & $*$ & $*$ & $*$ & $*$ & 2.01 \\
\hline & $\mathrm{A} 181 \mathrm{~T}$ & 1.55 & 2.83 & 2.38 & $*$ & 8.93 \\
\hline & A181V & 2.17 & 4.48 & 2.44 & $*$ & 11.47 \\
\hline & M204I & 2.18 & 3.65 & 2.66 & * & 1.56 \\
\hline & M204V & $*$ & $*$ & 1.04 & $*$ & $*$ \\
\hline & $\mathrm{N} 236 \mathrm{~T}$ & 44.00 & 75.58 & 51.83 & 45.87 & 47.23 \\
\hline & M250I & $*$ & 1.72 & 1.27 & $*$ & $*$ \\
\hline & M250L & $*$ & $*$ & $*$ & $*$ & $*$ \\
\hline
\end{tabular}


Table III. Continued.

\begin{tabular}{|c|c|c|c|c|c|c|}
\hline \multirow[b]{2}{*}{ Patient } & \multirow[b]{2}{*}{ Mutation site } & \multicolumn{5}{|c|}{ Mutation rates $(\%)$ at various weeks post-therapy } \\
\hline & & 0 & 24 & 36 & 48 & 96 \\
\hline \multirow{13}{*}{ Patient J } & L80I & $*$ & $*$ & $*$ & $*$ & $*$ \\
\hline & L80V & $*$ & $*$ & $*$ & $*$ & $*$ \\
\hline & L180M & $*$ & $*$ & $*$ & $*$ & $*$ \\
\hline & A181S & $*$ & 2.10 & $*$ & $*$ & $*$ \\
\hline & $\mathrm{A} 181 \mathrm{~T}$ & $*$ & 1.87 & $*$ & $*$ & $*$ \\
\hline & A181V & $*$ & $*$ & $*$ & $*$ & $*$ \\
\hline & M204I & $*$ & $*$ & $*$ & $*$ & $*$ \\
\hline & M204V & $*$ & $*$ & $*$ & $*$ & $*$ \\
\hline & N236T & $*$ & $*$ & $*$ & $*$ & $*$ \\
\hline & M250I & $*$ & $*$ & $*$ & $*$ & $*$ \\
\hline & M250L & $*$ & $*$ & $*$ & $*$ & $*$ \\
\hline & L80I & $*$ & $*$ & $*$ & $*$ & $*$ \\
\hline & L80V & $*$ & $*$ & $*$ & $*$ & $*$ \\
\hline \multirow[t]{11}{*}{ Patient K } & L180M & $*$ & $*$ & $*$ & a & a \\
\hline & A181S & $*$ & $*$ & $*$ & a & a \\
\hline & A181T & $*$ & $*$ & $*$ & a & a \\
\hline & A181V & $*$ & $*$ & $*$ & a & a \\
\hline & M204I & $*$ & $*$ & $*$ & a & a \\
\hline & M204V & $*$ & $*$ & $*$ & a & a \\
\hline & N236T & $*$ & $*$ & $*$ & a & $\mathrm{a}$ \\
\hline & M250I & $*$ & $*$ & $*$ & $\mathrm{a}$ & a \\
\hline & M250L & $*$ & $*$ & $*$ & $\mathrm{a}$ & $\mathrm{a}$ \\
\hline & L80I & $*$ & $*$ & $*$ & a & a \\
\hline & L80V & $*$ & $*$ & $*$ & a & a \\
\hline \multirow[t]{11}{*}{ Patient L } & L180M & $*$ & $*$ & $*$ & $*$ & $*$ \\
\hline & A181S & $*$ & $*$ & $*$ & $*$ & $*$ \\
\hline & $\mathrm{A} 181 \mathrm{~T}$ & $*$ & $*$ & $*$ & 1.36 & 1.95 \\
\hline & A181V & $*$ & $*$ & $*$ & $*$ & $*$ \\
\hline & M204I & $*$ & 1.33 & $*$ & 9.20 & 9.31 \\
\hline & M204V & $*$ & 1.30 & $*$ & $*$ & $*$ \\
\hline & N236T & $*$ & $*$ & $*$ & 5.31 & 5.52 \\
\hline & M250I & $*$ & $*$ & $*$ & $*$ & $*$ \\
\hline & M250L & $*$ & $*$ & $*$ & $*$ & $*$ \\
\hline & L80I & $*$ & $*$ & $*$ & $*$ & 3.35 \\
\hline & L80V & $*$ & $*$ & $*$ & $*$ & $*$ \\
\hline
\end{tabular}

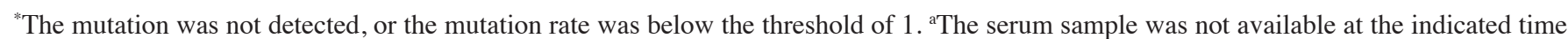
point. Patient information regarding the point at which viral breakthrough was first identified and when ADV was administered was as follows: A, Viral breakthrough was identified at week 36 and ADV was added at week 48; B, viral breakthrough was identified at week 36 and ADV was added at week 36; C, viral breakthrough was identified at week 36 and ADV was added at week 24 due to only a partial response; D, viral breakthrough was identified at week 36 and ADV was added at week 36; E, viral breakthrough was identified at week 36 and ADV was added at week 36; F, viral breakthrough was identified at week 36 and ADV was added at week 36; G, viral breakthrough was identified at week 24 and ADV was added at week 24; H, viral breakthrough was identified at week 36 and AVD was added at week 48; I, viral breakthrough was identified at week 48 and ADV was added at week 48; J, viral breakthrough was identified at week 36 and ADV was added at week 36; K, viral breakthrough was identified at week 48 and ADV was added at week 48; L, viral breakthrough was identified at week 24 and ADV was added at week 48. ADV, adefovir.

in which viral evolution may occur (21). However, the extent of mutation which is required to give rise to a virological breakthrough and the predominant dynamic pattern of viral evolution during virological breakthrough remain to be fully elucidated, largely as a consequence of the limitations of the current technology for detecting drug resistance. 

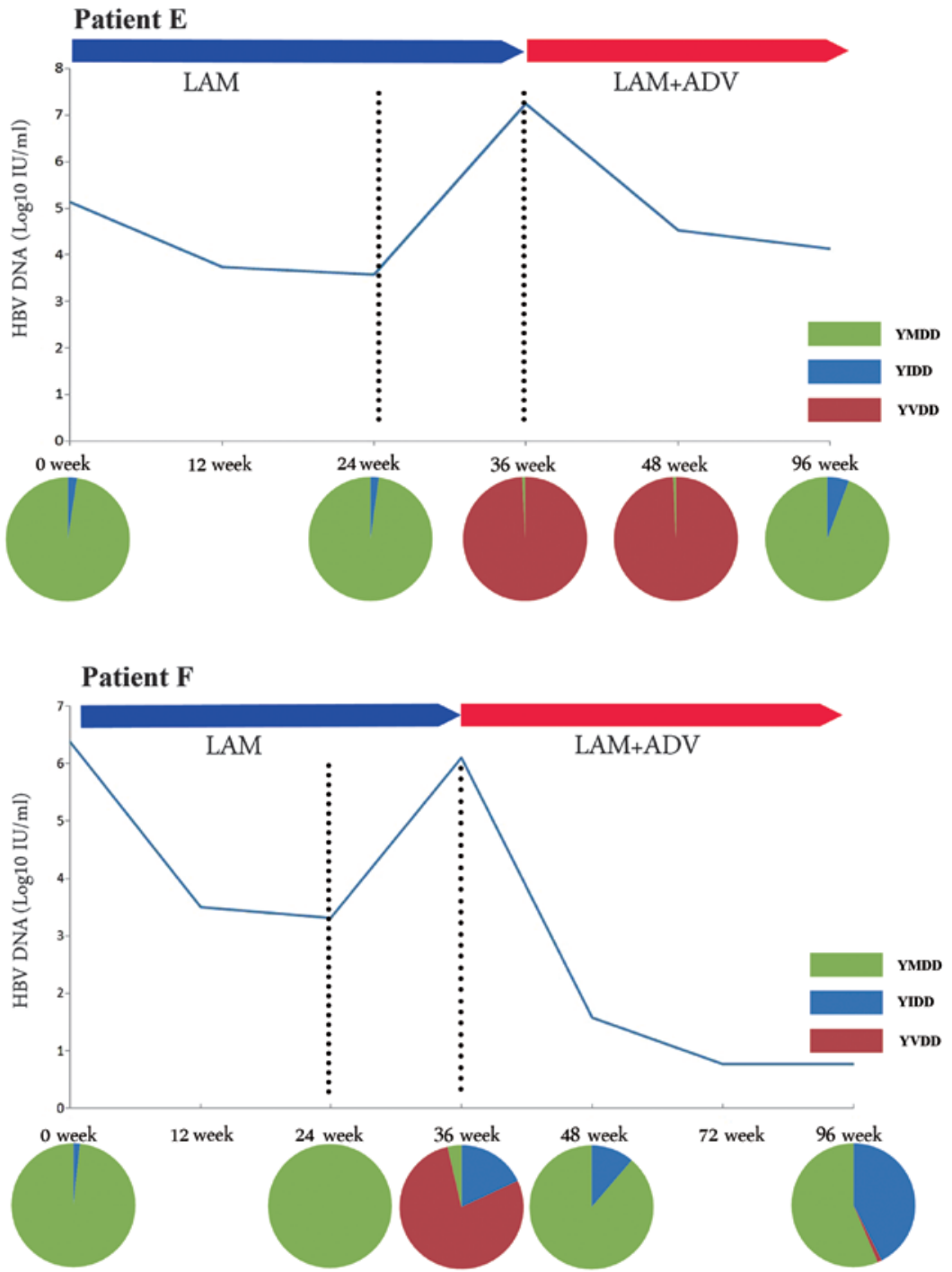

Figure 2. YVDD-motif-variant-dominated viral breakthrough in 4/12 patients in the present study. Patients E, F, G and $\mathrm{H}$ exhibited this type of viral breakthrough, although this figure only illustrates the data for patients $\mathrm{E}$ and $\mathrm{F}$. The virological breakthrough was predominantly caused by the YVDD motif variant, which reverted to the wild-type following combination therapy. ADV, adefovir; LAM, lamivudine; HBV, hepatitis B virus.

Previous studies focused on using UDPS to reveal the underlying mechanisms associated with HCV and HIV. An increasing number of studies are recruiting UDPS to detect minor mutations in $\mathrm{HBV}$, and these studies have demonstrated that UDPS is more sensitive as a technique for detecting minor mutations compared with previous technologies $(22,23)$. Notably, longitudinal studies focused on the dynamic evolution of the HBV DNA during treatment are limited, which may offer further insights into the mechanism underlying drug-associated resistance. UDPS was used previously to investigate the dynamic evolution pattern of HBV variants in patients with $\mathrm{CHB}$ who developed resistance to $\mathrm{ADV}$, and the viral loads were identified to consist of different types of HBV variants; furthermore, the absolute levels of these variants varied during the treatment with ADV (24). In the present study, it was demonstrated that the YMDD wild-type motif of HBV was almost entirely replaced by the LAM-resistant variants in eight patients following viral breakthrough, indicating that virological breakthrough was caused by the rapid replication of novel resistant variants.
The present study also revealed that the NUC-associated mutations existed in treatment-naive patients, for example, patient D, who exhibited a high mutation rate of M204I at the baseline.

In the present study, the LAM-induced virological breakthrough was further subdivided into three types, according to which variant dominated during viral breakthrough, and common characteristics were identified among the three types. The findings of the present study provided novel insights into the mechanism underlying the drug resistance and the virological breakthrough, however, this study also gives rise to further questions. Firstly, it was identified that the implementation of ADV add-on therapy resulted in an eventual reversion of the YVDD variant into wild-type YMDD, although the YIDD variant remained dominant. It is an open question whether patients who experienced YVDD variant-dominated viral breakthrough benefitted more from ADV add-on therapy compared with those who experienced the YIDD-variant-dominated viral breakthrough. Secondly, a previous study revealed that $\sim 40 \%$ of the virological 


\section{Patient I}

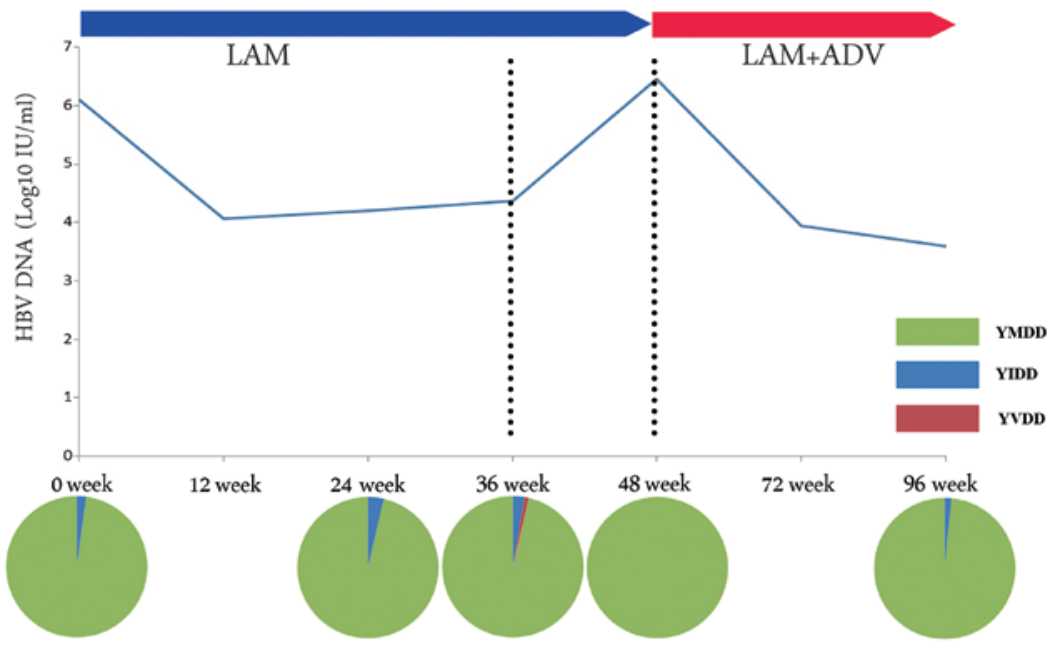

Patient J

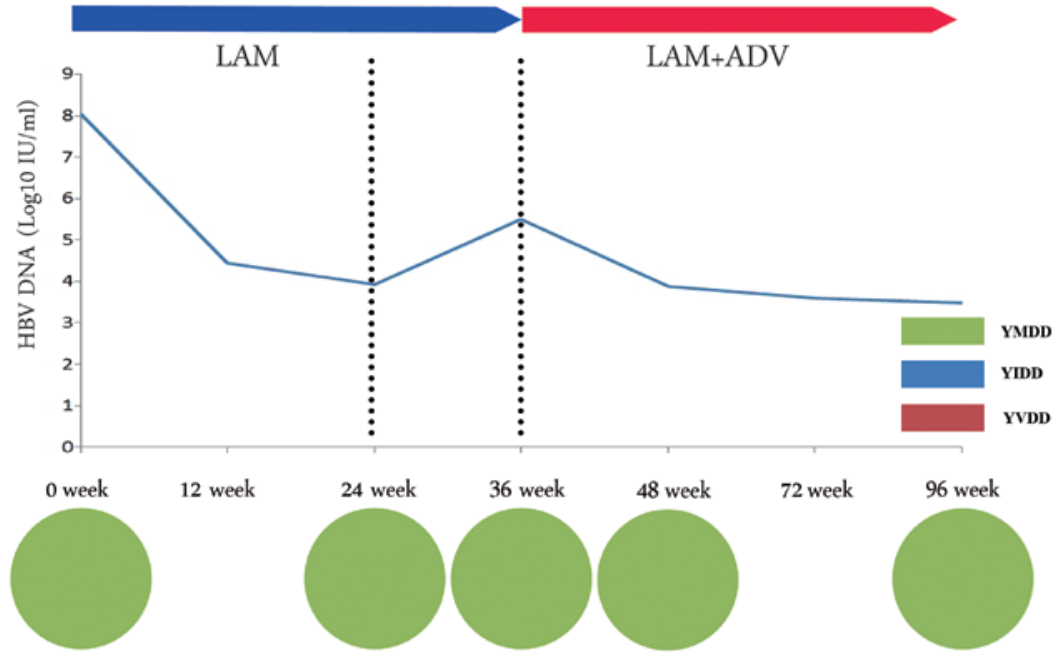

Figure 3. YMDD-wild-type-dominated viral breakthrough in 4/12 patients featured in the present study. Virological breakthrough was caused by the YMDD wild-type motif in patients I, J, K and L, although only patients I and $\mathrm{J}$ are illustrated in the figure. ADV, adefovir; LAM, lamivudine; HBV, hepatitis B virus.

breakthroughs in patients receiving NUCs were not associated with drug resistance during clinical practice, which the authors of the study suggested was caused by medication adherence (25). However, the adherence profile of the patients in the present study was examined during the treatment, and virological breakthrough was revealed to be caused by YMDD wild-type-dominated variants. Therefore, LAM-resistance-associated mutation sites remain to be identified, and the mechanism underlying the phenomenon remains to be elucidated. Thirdly, it was revealed that the mutation sites, rt80 and rt180, were able to compensate for rt204 in patients who developed LAM resistance (26), a result which was further confirmed in the present study. Additionally, the present study revealed that YVDD-variant-dominated virological breakthrough was closely associated with the L180M mutation, and an identical trend in the changes of the M204V and L180M mutations was observed, which raised the question of the specific mechanism of rt204 and its supplementary sites. Taken together, the present study provided novel insights into the mechanism underlying virological breakthrough and the evolution pattern of HBV DNA during antiviral therapy.
However, the present study was limited by the small number of enrolled patients, and therefore a larger cohort study in the future will be useful to substantiate these results.

In 2007, 'the roadmap concept' was recommended for the treatment of patients with $\mathrm{CHB}$, which entailed using early virological responses to optimize long-term outcomes for patients with CHB (27). Previous studies demonstrated that patients may benefit more from treatment strategies with NUCs which are guided by the roadmap concept (28-30). Notably, the present study revealed that virological breakthrough may be caused by the rapid replication of the drug-resistant variants selected by the treatment with NUCs, including YIDD- and YVDD-variant-dominated viral breakthroughs. Therefore, more frequent and earlier monitoring of the level of the HBV DNA level and the viral mutation rate are urgently required in patients who experience suboptimal treatment responses during the treatment with NUCs. Taken together, the results from the present study may assist in improving current understanding of HBV evolution during NUC treatment and contribute to the development of novel treatment strategies. 


\section{Acknowledgements}

The present study was partly supported by the Key Medical Specialties Found of Shanghai Municipal Health Bureau (no. 05II011 2-1). The authors would like to thank Dr Keguang Chen (Department of Otorhinolaryngology-Head and Neck Surgery, Eye and ENT Hospital, Fudan University (Shanghai, China) for editing the figures in this paper.

\section{References}

1. Lavanchy D: Hepatitis B virus epidemiology, disease burden, treatment and current and emerging prevention and control measures. J Viral Hepat 11: 97-107, 2004

2. Trépo C, Chan HL and Lok A: Hepatitis B virus infection. Lancet 384: 2053-2063, 2014.

3. Tujios SR and Lee WM: Update in the management of chronic hepatitis B. Curr Opin Gastroenterol 29: 250-256, 2013.

4. Ma H and Jia J: Why do I treat HBeAg-positive chronic hepatitis B patients with a nucleoside analogue. Liver Int 33 (Suppl 1): S133-S136, 2013.

5. Fung J, Lai CL, Seto WK and Yuen MF: Nucleoside/nucleotide analogues in the treatment of chronic hepatitis B. J Antimicrob Chemother 66: 2715-2725, 2011.

6. Chotiyaputta W and Lok AS: Hepatitis B virus variants. Nat Rev Gastroenterol Hepatol 6: 453-462, 2009.

7. Rodriguez-Frias F, Buti M, Tabernero D and Homs M: Quasispecies structure, cornerstone of hepatitis B virus infection: Mass sequencing approach. World J Gastroenterol 19: 6995-7023, 2013.

8. Capobianchi MR, Giombini E and Rozera G: Next-generation sequencing technology in clinical virology. Clin Microbiol Infect 19: 15-22, 2013

9. Abbate I, Rozera G, Tommasi C, Bruselles A, Bartolini B, Chillemi G, NicastriE, Narciso P, Ippolito G and Capobianchi MR: Analysis of co-receptor usage of circulating viral and provira HIV genome quasispecies by ultra-deep pyrosequencing in patients who are candidates for CCR5 antagonist treatment. Clin Microbiol Infect 17: 725-731, 2011.

10. Armenia D, Vandenbroucke I, Fabeni L, Van Marck H, Cento V, D'Arrigo R, Van Wesenbeeck L, Scopelliti F, Micheli V,Bruzzone B, et al: Study of genotypic and phenotypic HIV-1 dynamics of integrase mutations during raltegravir treatment: A refined analysis by ultra-deep 454 pyrosequencing. J Infect Dis 205: 557-567, 2012.

11. Trimoulet P, Pinson P, Papuchon J, Foucher J, Vergniol J, Chermak F, Wittkop L, Castaing N, Merrouche W, Reigadas S, et al: Dynamic and rapid changes in viral quasispecies by UDPS in chronic hepatitis $\mathrm{C}$ patients receiving telaprevir-based therapy. Antivir Ther 18: 723-727, 2013.

12. Applegate TL, Gaudieri S, Plauzolles A, Chopra A, Grebely J, Lucas M, Hellard M, Luciani F, Dore GJ and Matthews GV: Naturally occurring dominant drug resistance mutations occur infrequently in the setting of recently acquired hepatitis $\mathrm{C}$. Antivir Ther 20: 199-208, 2015.

13. Cortes KC, Zagordi O, Perlejewski K, Laskus T, Maroszek K, Bukowska-Ośko I, Pawełczyk A, Płoski R, Berak H, Horban A and Radkowski M: Deep sequencing of hepatitis $\mathrm{C}$ virus hypervariable region 1 reveals no correlation between genetic heterogeneity and antiviral treatment outcome. BMC Infect Dis 14: 389, 2014.

14. Wang H, Ji YY, Yao GB, Ma XY, Xie Q, Pang HY, Wu SM, Li J, Chen CW, Xu XW and Gu EL: Two years efficiency of lamivudine and adefovir dipivoxil combined therapy in chronic hepatitis B patients. Eur Rev Med Pharmacol Sci 17: 636-643, 2013.
15. European Association For The Study Of The Liver: EASL clinical practice guidelines: Management of chronic hepatitis B virus infection. J Hepatol 57: 167-185, 2012.

16. Wu J, Liu W, He L, Huang F, Chen J, Cui P, Shen Y, Zhao J, Wang W, Zhang Y, et al: Sputum microbiota associated with new, recurrent and treatment failure tuberculosis. PLoS One 8: e83445, 2013.

17. Hamady M and Knight R: Microbial community profiling for human microbiome projects: Tools, techniques, and challenges. Genome Res 19: 1141-1152, 2009.

18. Zoulim F and Locarnini S: Hepatitis B virus resistance to nucleos(t)ide analogues. Gastroenterology 137: 1593-1608.e1-e2, 2009.

19. Rhee SY, Margeridon-Thermet S, Nguyen MH, Liu TF, Kagan RM, Beggel B, Verheyen J, Kaiser R and Shafer RW: Hepatitis B virus reverse transcriptase sequence variant database for sequence analysis and mutation discovery. Antiviral Res 88: 269-275, 2010.

20. Chan HL and Jia J: Chronic hepatitis B in Asia-new insights from the past decade. J Gastroenterol Hepatol 26 (Suppl 1): 131-137, 2011.

21. Wargo AR and Kurath G: Viral fitness: Definitions, measurement, and current insights. Curr Opin Virol 2: 538-545, 2012.

22. Gong L, Han Y, Chen L, Liu F, Hao P, Sheng J, Li XH, Yu DM, Gong QM, Tian F, et al: Comparison of next-generation sequencing and clone-based sequencing in analysis of hepatitis $B$ virus reverse transcriptase quasispecies heterogeneity. J Clin Microbiol 51: 4087-4094, 2013.

23. Ramírez C, Gregori J, Buti M, Tabernero D, Camós S, Casillas R, Quer J, Esteban R, Homs M and Rodriguez-Frías F: A comparative study of ultra-deep pyrosequencing and cloning to quantitatively analyze the viral quasispecies using hepatitis B virus infection as a model. Antiviral Res 98: 273-283, 2013.

24. Rodriguez C, Chevaliez S, Bensadoun P and Pawlotsky JM: Characterization of the dynamics of hepatitis $\mathrm{B}$ virus resistance to adefovir by ultra-deep pyrosequencing. Hepatology 58: 890-901, 2013

25. Hongthanakorn C, Chotiyaputta W, Oberhelman K, Fontana RJ, Marrero JA, Licari T and Lok AS: Virological breakthrough and resistance in patients with chronic hepatitis $\mathrm{B}$ receiving nucleos(t)ide analogues in clinical practice. Hepatology 53: 1854-1863, 2011.

26. Menendez-Arias L, Alvarez $M$ and Pacheco B: Nucleoside/nucleotide analog inhibitors of hepatitis B virus polymerase: mechanism of action and resistance. Curr Opin Virol 8: 1-9, 2014.

27. Keeffe EB, Zeuzem S, Koff RS, Dieterich DT, Esteban-Mur R, Gane EJ, Jacobson IM, Lim SG, Naoumov N, Marcellin P, et al: Report of an international workshop: Roadmap for management of patients receiving oral therapy for chronic hepatitis B. Clin Gastroenterol Hepatol 5: 890-897, 2007.

28. Lo AO, Wong VW, Wong GL, Chan HY, Cheung CM and Chan HL: Efficacy of entecavir switch therapy in chronic hepatitis B patients with incomplete virological response to telbivudine. Antivir Ther 18: 671-679, 2013.

29. Piratvisuth T, Komolmit P, Tanwandee T, Sukeepaisarnjaroen W, Chan HL, Pessôa MG, Fassio E, Ono SK, Bessone F, Daruich J, et al: 52-week efficacy and safety of telbivudine with conditional tenofovir intensification at week 24 in HBeAg-positive chronic hepatitis B. PLoS One 8: e54279, 2013.

30. Sun J, Xie Q, Tan D, Ning Q, Niu J, Bai X, Fan R, Chen S, Cheng J, Yu Y, et al: The 104-week efficacy and safety of telbivudine-based optimization strategy in chronic hepatitis B patients: A randomized, controlled study. Hepatology 59: 1283-1292, 2014. 